\title{
Combined Effect of Active Cycle of Breathing Technique and Autogenic Drainage on PEFR and Inspiratory Capacity in Participants Following Upper Abdominal Surgery - A Randomized Controlled Clinical Trial Study
}

\author{
P. S. ManiArasi ${ }^{1}$, V. P. Hathila ${ }^{2}$, D. Jayaprakash ${ }^{3}$ \\ ${ }^{1} \mathrm{PhD}$ Scholar in Parul University, Gujarat, India; and Professor in Physiotherapy, Government Physiotherapy \\ College, Nimnaliya Road, Muvaliya, Dahod -389160, Gujarat. \\ ${ }^{2}$ Professor and Head, Dept of Surgery, Parul institute of Medical Sciences and Research, P.O Limda, Waghodia, \\ Vadodara-391760, Gujarat, India. \\ ${ }^{3}$ Principal I/C and Professor in Physiotherapy, Government Physiotherapy College, Nimnaliya Road, Muvaliya, \\ Dahod -389160, Gujarat. \\ Corresponding Author: P.S. ManiArasi
}

DOI: https://doi.org/10.52403/ijhsr.20220204

\begin{abstract}
Background: The purpose of the study is to find the Combined effect of Active cycle of breathing technique and Autogenic drainage on PEFR and inspiratory capacity in participants following upper abdominal surgery. Post-operative pulmonary complications are common which increases the patients mortality. Changes in the respiratory system determines the risk factors of complications. These risk factors can be modified or reduced by the immediate post-operative management given to the patient at an early stage which can be aimed in improving the lung volume and clearance of secretions. Early physiotherapy is believed to reduce the pulmonary complications following major surgery. Lung function which is declined due to anaesthetic effect and the incisional pain which alters the normal ventilatory function in abdominal surgery. Therefore, the study is aimed to analyse the outcomes of peak expiratory flow rate and inspiratory capacity in participants subjected to upper abdominal surgery on performing Active cycle of breathing technique and autogenic drainage in the postoperative period.

Methods: 30 subjects between the age of 30 to 60 years who have undergone urgent and elective abdominal surgery were included in the study. 15 subjects were given Active cycle of breathing technique while another 15 subjects were given both Active cycle of breathing technique and autogenic drainage. The exercises were given for a period of 6 days, and the outcome measure of PEFR and Inspiratory capacity are measured on the first day and 6th day for the comparison. Statistical analysis was done using student's " $t$ " test.

Results: The subjects who had performed only Active cycle of breathing technique for a period of 6 days shown significant improvement in both PEFR and inspiratory capacity. Similarly, the subjects who performed both Active cycle of breathing technique and autogenic drainage also shown improvement on PEFR and inspiratory capacity. The PEFR on the Day 6 in Group B $(338 \pm 52.81)$ had significant difference than Group A where the PEFR was $(263.33 \pm 47.61)$. The inspiratory capacity on the Day 6 in Group B $(2273.33 \pm 201.66)$ had significant difference than Group A where the inspiratory capacity was $(2106.67 \pm 190.74)$

Conclusion: The above study had proved that combined techniques of Active cycle of breathing technique and autogenic drainage increases the peak expiratory flow rate and inspiratory capacity, the
\end{abstract}


P. S. ManiArasi et.al. Combined effect of active cycle of breathing technique and autogenic drainage on PEFR and inspiratory capacity in participants following upper abdominal surgery - a randomized controlled clinical trial study.

lung function which helps to reduce the post-operative pulmonary complications in participants who have undergone upper abdominal surgery. This accepts the alternate hypothesis.

Keywords: Active cycle of breathing technique, Autogenic drainage, Peak expiratory flow rate, Inspiratory capacity, Upper abdominal surgery.

\section{INTRODUCTION}

Abdominal surgery involves the opening of an abdomen for performing operations or procedures on the organs including the stomach, gall bladder, small or large intestine, liver, pancreas, spleen and appendix. Abdominal surgery can be performed due to infection, pain, any obstruction or tumour growth. Upper abdominal surgeries are the surgeries performed in the upper region of the abdomen above the umbilicus which are epigastrium, right hypochondrium and left hypochondrium $^{[1]}$. Post-operative pulmonary complications are very common in upper abdominal surgery with the incidence of 22 to $40 \%$ than lower abdominal surgery with $2-5 \%{ }^{[2]}$. Surgical procedures performed in the abdomen of affects respiratory muscles, it's coordinated motion of the chest wall that causes loss of muscle integrity and the disturbance in thoracoabdominal mechanics. Due to this reason, there is a reduction in lung volumes with a rapid shallow breathing that has an effect on a decrease in trans diaphragmatic pressure, expiratory pressure and inspiratory pressures following upper abdominal surgery. Diaphragm is the main muscle that is affected during upper abdominal surgery ${ }^{[3]}$. Due to the effect of anaesthesia and pain suppresses the action of diaphragm leads to reduction in its strength which limits the normal breathing and forceful expiratory maneuver. This dysfunction causes of reduction in vital capacity, tidal volume and the total lung capacity that produces coughing mechanism insufficient to clear the secretions. This impairment in mucociliary clearance reduces the cough effectiveness with more secretion collection developing the atelectasis with a drop of oxygen saturation. The mucus which builds up on airway surfaces restricts the lungs ability for transportation of gases in and out of the lungs. When the secretions are not been cleared leads to the development of atelectasis and later pneumonia which becomes the major cause of pulmonary complications following surgery.

Forced expiratory maneuver is mandatory for expectorating the secretions collected beyond the alveoli, therefore a deep breathing maneuver is adopted before the intervention of forced expiratory technique. An incentive spirometry is a handheld medical device with the principle of sustained maximal inspiration (SMI) involving the person to perform a slow deep inspiration from the functional residual capacity up to the total lung capacity with a breath hold of three to 5 seconds. It is incorporated with a visual feedback of performance to monitor the inspiratory effort performed by the patient. Incentive spirometry facilitates the sustained slow deep breath. Incentive spirometry is combined and used along with deep breathing techniques to prevent postoperative pulmonary complications routine use of incentive spirometry and deep breathing exercises prevents atelectasis in patients following upper abdominal surgery. Post-operative chest physiotherapy helps to prevent atelectasis and improves airway clearance thereby increases the lung volume. The long slow deep breaths with breath holding decreases the intrapleural pressure that helps in alveolar expansion and gas exchange ${ }^{[4]}$.

Active cycle of breathing technique is a therapeutic exercise that are performed by the patients when there is an excess secretions present in the lungs that needs to be expectorated or cleared. This also helps to improve the lung ventilation. The active cycle of breathing technique is a combination of three components of 
exercises including breathing control, thoracic expansion exercises followed by huffing. The forced expiratory technique which plays an integral part in the active cycle of breathing technique helps to promote the movement of secretions through high and low volume huffing by changing the intrathoracic pressure and an altered airway dynamics. ${ }^{[5]}$ The Physiology behind the breathing control is reduction of work of breathing and improvement of oxygenation due to slow and relaxed breathing. The bronchospasm is prevented by the period of breathing control. The thoracic expansion exercises promote collateral ventilation by allowing the air to get behind the secretions collected in the alveoli and assist in loosening and mobilising the secretions which in turn increases the lung volume. By the change in intrathoracic pressure on performing huffing causes secretion clearance.

Autogenic drainage is a selfdrainage technique which is used as an airway clearance method by using different lung volumes. It is characterised by breath control that aims the patient to adjust the respiratory rate, depth and lung volumes during breathing ${ }^{[6]}$. This helps in mobilising the secretions and brings to the central airways for expectoration. Various exploratory flow rates at different lung volumes are used to prevent the airwave from closure, the mucus gets mobilised and moved to the central airways. The technique consists of three phases,

i) breathing at low lung volume in the expiratory reserve volume to mobilise or loosen the secretions in the peripheral airways $\rightarrow$ Unsticking phase.

ii) breathing at low to mid lung volume to collect the secretions from the peripheral airways to the central airways $\rightarrow$ Collecting phase.

iii) breathing at mid to high lung volume in the inspiratory volume to remove the secretions from the central airways $\rightarrow$ Evacuating phase.

The shearing forces in the airways due to the changes in lung volumes helps in mobilising the secretions from the smaller airways and moves to the larger airways.

It is well documented that early physiotherapy and care helps to prevent the pulmonary complications following surgery. The major problem that arises in upper abdominal surgery is respiratory dysfunction with reduced expiratory maneuver that increases the collection of secretions in the lungs, becomes the developmental stage of atelectasis and pneumonia. To prevent this the patient should be trained the diaphragmatic function, breathing exercises, to cough effectively from the early post-operative period to prevent the accumulation of secretions. To know the effectiveness of forced expiratory effort PEFR (Peak expiratory flow rate) can be used. It is the maximum flow rate during a FVC (Forced Vital Capacity) manoeuvre. It is the highest rate at which the gas is expelled from the lungs through an open mouth. It is a very reliable indicator of lung ventilation. It is used as an essential tool in the measurement and outcome predictor of lung function. ${ }^{[7]}$

Inspiratory capacity is the volume difference between the total lung capacity and the functional residual capacity. It is the maximum volume of air that a person can inhale from a tidal expiration. It is an important physiological parameter in many clinical implications ${ }^{[8]}$. The reduced inspiratory capacity occurs due to air trapping in the alveoli this leads to the symptoms of dyspnoea that lowers exercise capacity and leads to poor quality of life $\mathrm{e}^{[9]}$. Inspiratory capacity and vital capacity are clinically relevant. The common protocol following surgery is the use of incentive spirometry and deep breathing exercises. The common protocol following surgery is the use of incentive spirometry and deep breathing exercises. Though there is an improvement in the patient's lung function following the regular intervention but the significance of improvement is less. To improve the lung function with prevention of pulmonary complications following upper abdominal surgery, the persons 

and inspiratory capacity in participants following upper abdominal surgery - a randomized controlled clinical trial study.

expiratory effort should be efficient. Therefore, to facilitate and promote the lung function, intervention of Active cycle of breathing technique and Autogenic drainage is prescribed. There are limited supportive studies to prove the effectiveness of Active cycle of breathing technique and Autogenic drainage to improve PEFR changes and inspiratory capacity in upper abdominal surgery patients. So in this study it was aimed to note the combined effect of Active cycle of breathing technique (ACBT) and Autogenic drainage (AD) in improving lung function (PEFR) and inspiratory capacity to prevent postoperative pulmonary complications in participants who have undergone upper abdominal surgery.

\section{Statement of the problem}

Active cycle of breathing technique and Autogenic drainage is a very safe and easy intervention method that can be followed and practiced by the patients on improving peak expiratory flow rate and inspiratory capacity in subjects who have undergone upper abdominal surgery.

\section{Objective}

To evaluate the effectiveness of Active cycle of breathing technique and Autogenic drainage in improving the peak expiratory flow rate and inspiratory capacity in upper abdominal surgery patients.

\section{Hypothesis \\ Null hypothesis}

There are no significant improvements in peak expiratory flow rate and inspiratory capacity following Active cycle of breathing technique and Autogenic drainage in subjects following upper abdominal surgery.

\section{Alternate hypothesis}

There are no significant improvements in peak expiratory flow rate and inspiratory capacity following Active cycle of breathing technique and Autogenic drainage in subjects following upper abdominal surgery.

\section{Need of the study}

Subjects who perform Active cycle of breathing technique and Autogenic drainage together following upper abdominal surgery has significant benefits in improving lung function, the quality of life, reduce the length of hospital stay and prevention of post-operative pulmonary complications.

\section{MATERIALS AND METHODOLOGY}

A randomized controlled trial study was conducted at Civil Hospital, Dahod undertaken by Zydus Medical College from January 2021 - September 2021. Ethical clearance was obtained from the Institutional ethical committee. written consent was taken from all 30 patients who were included in the study. Subjects of both genders were included for the study. 30 subjects with the age group between 30 to 60 years who have undergone emergency and elective upper abdominal surgery were included in this study. Unstable and complicated abdominal surgical patients, laparoscopy patients, age more than 65 years, case of chronic respiratory diseases, cardiovascular diseases, neurological conditions and musculoskeletal problems were excluded in the study. By random sampling they were divided into two groups with 15 in each group. Group A $(n=15)$ were given Active cycle of breathing technique 3-4 cycles/day, Incentive spirometry (10 times with 3 secs hold every 4 waking hours) and Breathing Exercises (diaphragmatic breathing exercises prior and after incentive spirometry) for 6 days post operatively, while Group B $(\mathrm{n}=15)$ were given Autogenic drainage for 15- 20 minutes of 5-6 cycles, Incentive spirometry and Breathing Exercises and Active cycle of breathing technique 3-4 cycles/day. The outcome measure of PEFR (1/min) and Inspiratory capacity were recorded on the day 1 and at the end of sixth day. The collected data were tabulated and analysed using student's " $t$ " test that will compare the effects of PEFR, Inspiratory capacity and Pain between the two groups by Unpaired 
P. S. ManiArasi et.al. Combined effect of active cycle of breathing technique and autogenic drainage on PEFR and inspiratory capacity in participants following upper abdominal surgery - a randomized controlled clinical trial study.

" $t$ " test and within the groups by Paired " $t$ " test. The results were analysed and interpretations established to check the significance.

\section{RESULTS}

Demographic data

Table 1: Demographic data(n=30)
\begin{tabular}{|l|l|l|}
\hline Characteristics & GROUP A $(\mathbf{n}=\mathbf{1 5})$ & GROUP B $(\mathbf{n}=\mathbf{1 5})$ \\
\hline Age $($ years) & $43.07 \pm 7.33$ & $42.73 \pm 6.82$ \\
\hline Height $(\mathbf{c m})$ & $152.8 \pm 3.38$ & $153.13 \pm 3.31$ \\
\hline Weight $(\mathbf{k g})$ & $53.27 \pm 2.71$ & $53.67 \pm 3.9$ \\
\hline BMI & $22.83 \pm 1.30$ & $22.88 \pm 1.41$ \\
\hline
\end{tabular}

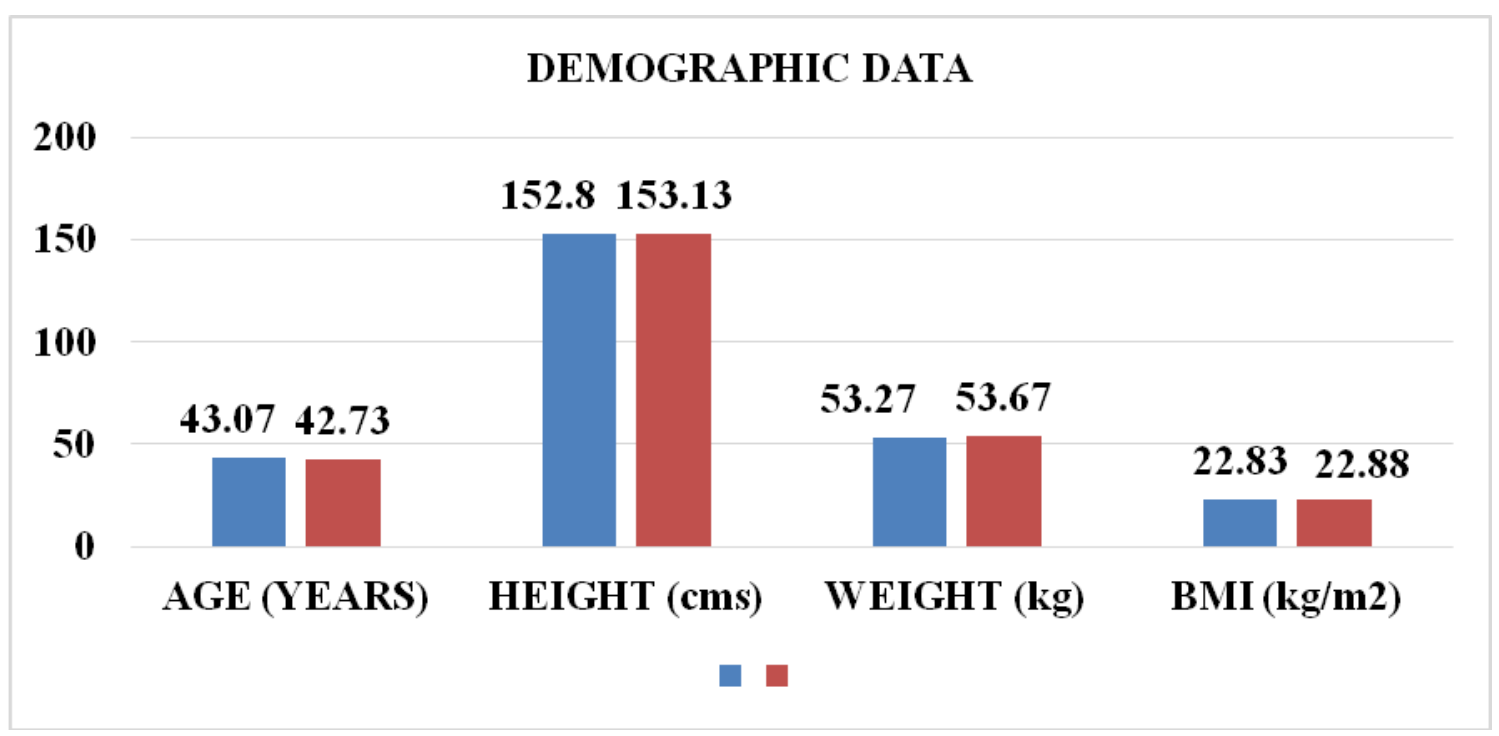

\section{Gender distribution}

Table 2: Gender distribution $(\mathbf{n}=\mathbf{3 0})$
\begin{tabular}{|l|l|l|}
\hline Sex & GROUP A (n=15) & GROUP B (n=15) \\
\hline Male & $9(60 \%)$ & $7(47 \%)$ \\
\hline Female & $6(40 \%)$ & $8(53 \%)$ \\
\hline
\end{tabular}

GENDER DISTRIBUTION

$\square$ MALE $\square$ FEMALE

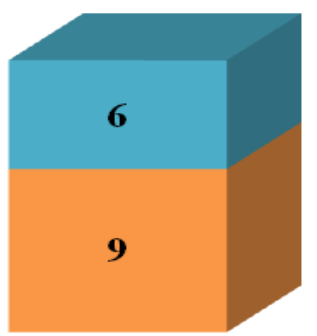

ACBT

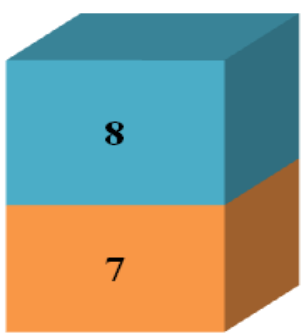

ACBT \& AD

\section{PEFR (L/Min)}

Table 3: Comparison of PEFR within the groups

\begin{tabular}{|c|c|c|c|c|c|c|c|c|}
\hline & \multicolumn{4}{|c|}{ GROUP A $(n=15)$} & \multicolumn{4}{|c|}{ GROUP B $(n=15)$} \\
\hline & Mean \pm SD & t-value & p-value & $\begin{array}{l}\text { Statistical } \\
\text { significance }\end{array}$ & Mean \pm SD & t-value & p-value & $\begin{array}{l}\text { Statistical } \\
\text { significance }\end{array}$ \\
\hline Day 1 & $112.67 \pm 12.23$ & \multirow[t]{2}{*}{13.2646} & \multirow[t]{2}{*}{0.0001} & \multirow{2}{*}{$\begin{array}{l}\text { Significant } \\
\text { difference }\end{array}$} & $110.67 \pm 13.87$ & \multirow[t]{2}{*}{15.9438} & \multirow[t]{2}{*}{0.0001} & \multirow{2}{*}{$\begin{array}{l}\text { Significant } \\
\text { difference }\end{array}$} \\
\hline Day 6 & $263.33 \pm 47.61$ & & & & $338 \pm 52.81$ & & & \\
\hline
\end{tabular}


P. S. ManiArasi et.al. Combined effect of active cycle of breathing technique and autogenic drainage on PEFR and inspiratory capacity in participants following upper abdominal surgery - a randomized controlled clinical trial study.

The above table shows that there is a significant difference of PEFR exists within both the group, in Group A the " $t$ " value 13.2646 and in Group B the " $t$ " value is 15.9438 and " $p$ " value $(0.0001)<0.05$.

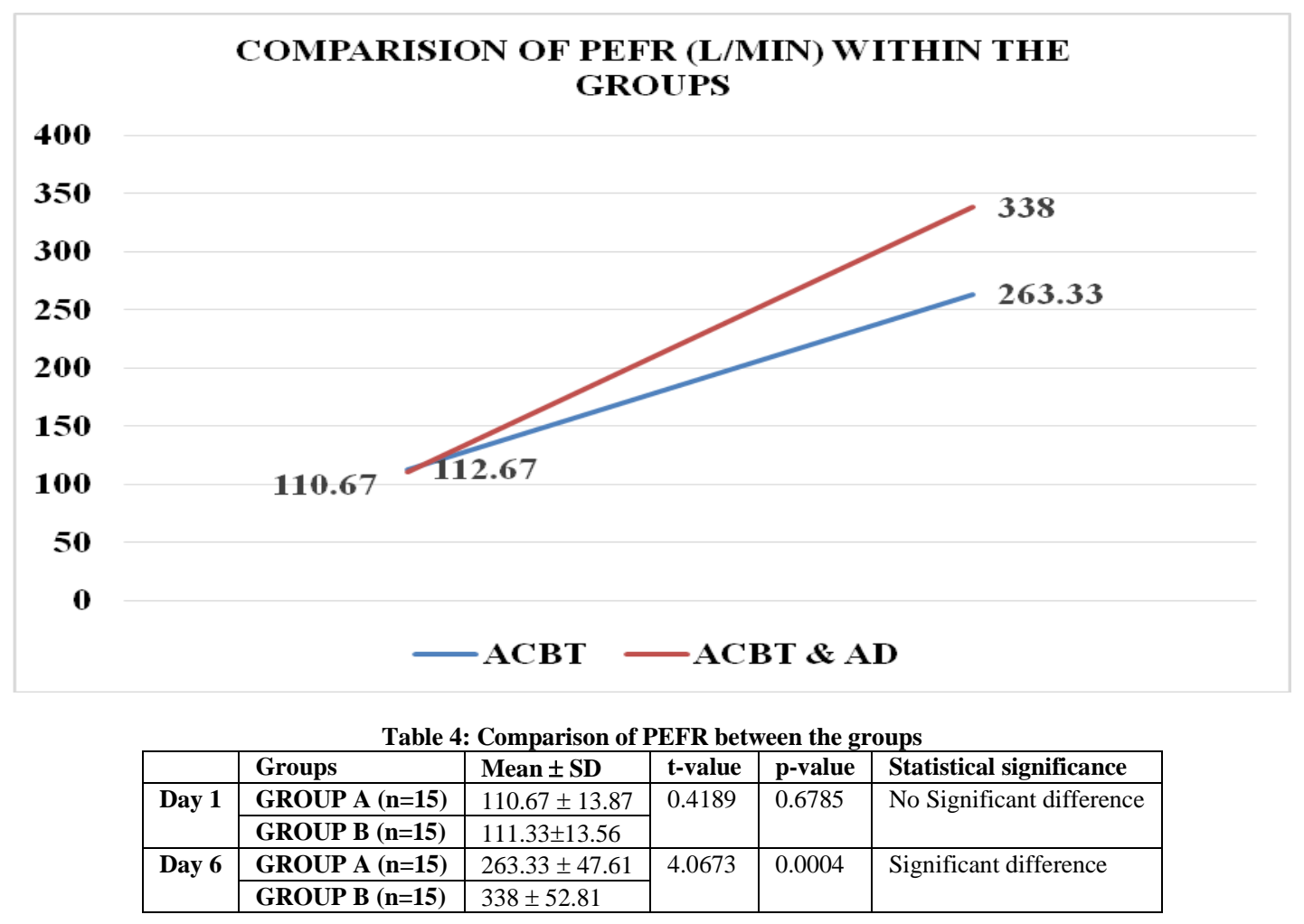

When comparing the PEFR values in Day 1 in both groups, there shows no significant difference between the group, as the "p" value $(0.6785)>0.05$ and " $t$ " value 0.4189 , while PEFR values in Day 6 shows significant difference between the groups with " $p$ " value $(0.0004)<0.05$ and " $t$ " value 4.0673 .

\section{COMPARISION OF PEFR (L/MIN) BETWEEN THE GROUPS}

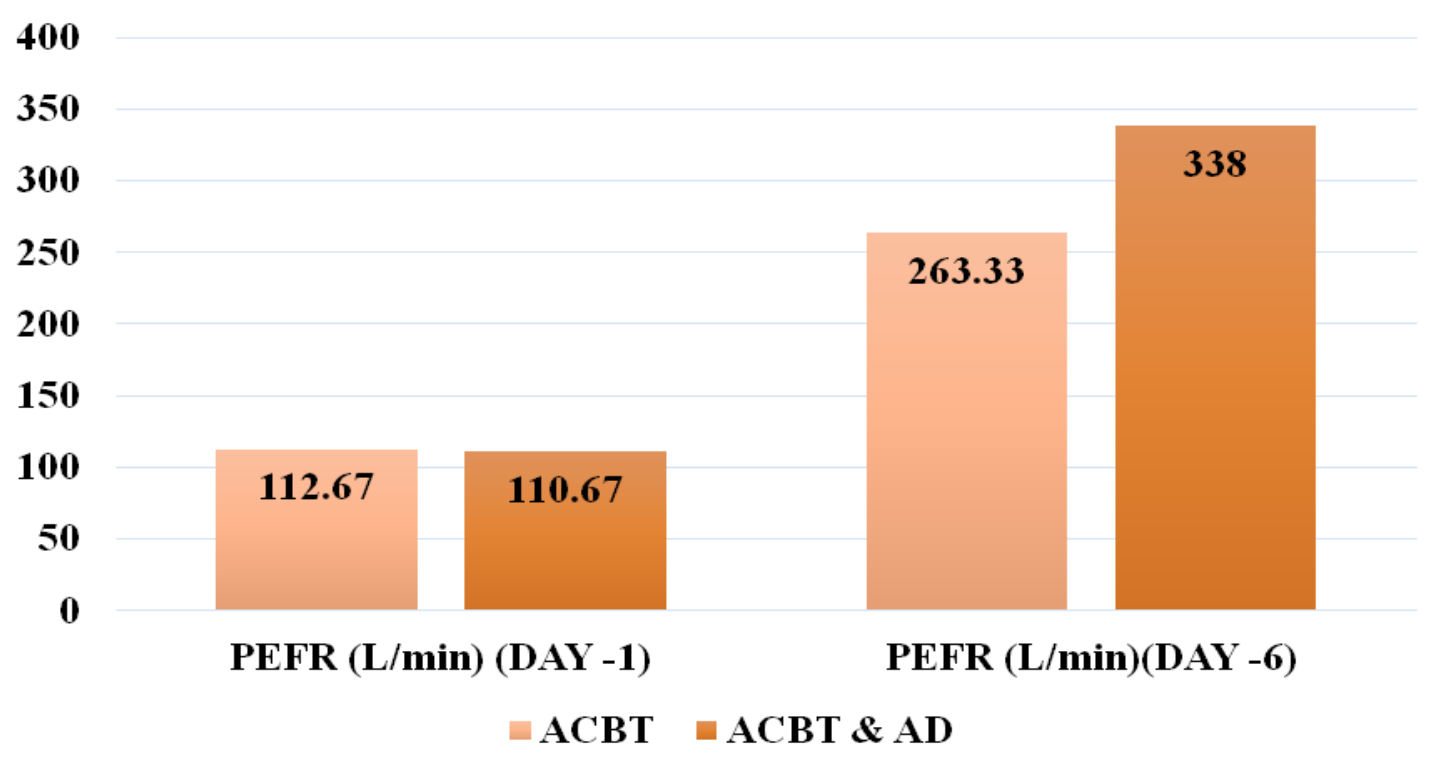


P. S. ManiArasi et.al. Combined effect of active cycle of breathing technique and autogenic drainage on PEFR and inspiratory capacity in participants following upper abdominal surgery - a randomized controlled clinical trial study.

\begin{tabular}{|c|c|c|c|c|c|c|c|c|}
\hline & \multicolumn{4}{|l|}{ GROUP A $(n=15)$} & \multicolumn{4}{|l|}{ GROUP B (n=15) } \\
\hline & Mean \pm SD & t-value & p-value & $\begin{array}{l}\text { Statistical } \\
\text { significance }\end{array}$ & Mean \pm SD & t-value & p-value & $\begin{array}{l}\text { Statistical } \\
\text { significance }\end{array}$ \\
\hline Day 1 & $1346.67 \pm 168.47$ & 11.264 & 0.0001 & Significant & $1266.67 \pm 149.6$ & 14.1071 & 0.0001 & Significant \\
\hline Day 6 & $2106.67 \pm 190.74$ & & & difference & $2273.33 \pm 201.66$ & & & difference \\
\hline
\end{tabular}

The above table shows that there is a 11.264 and in Group B the " $t$ " value is significant difference of PEFR exists within 14.1071 and "p" value $(0.0001)<0.05$. both the group, in Group A the " $\mathrm{t}$ " value

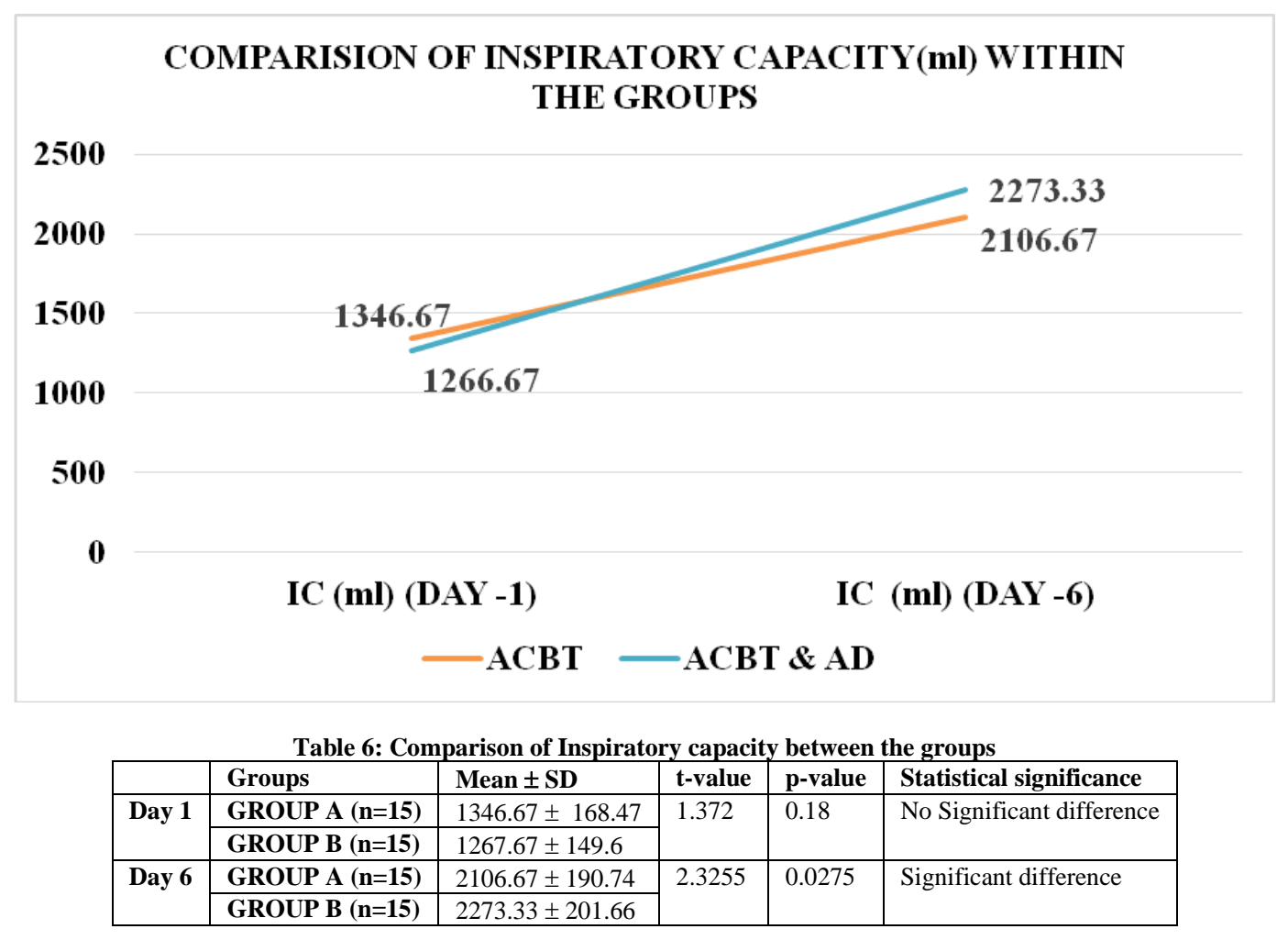

When comparing the PEFR values in Day 1 in both groups, there shows no significant difference between the group, as the "p" value $(0.18)>0.05$ and "t" value
1.372, while PEFR values in Day 6 shows significant difference between the groups with "p" value $(0.0275)<0.05$ and " $t$ " value 2.3255 .

\section{COMPARISION OF INSPIRATORY CAPACITY(ml) BETWEEN THE GROUPS}

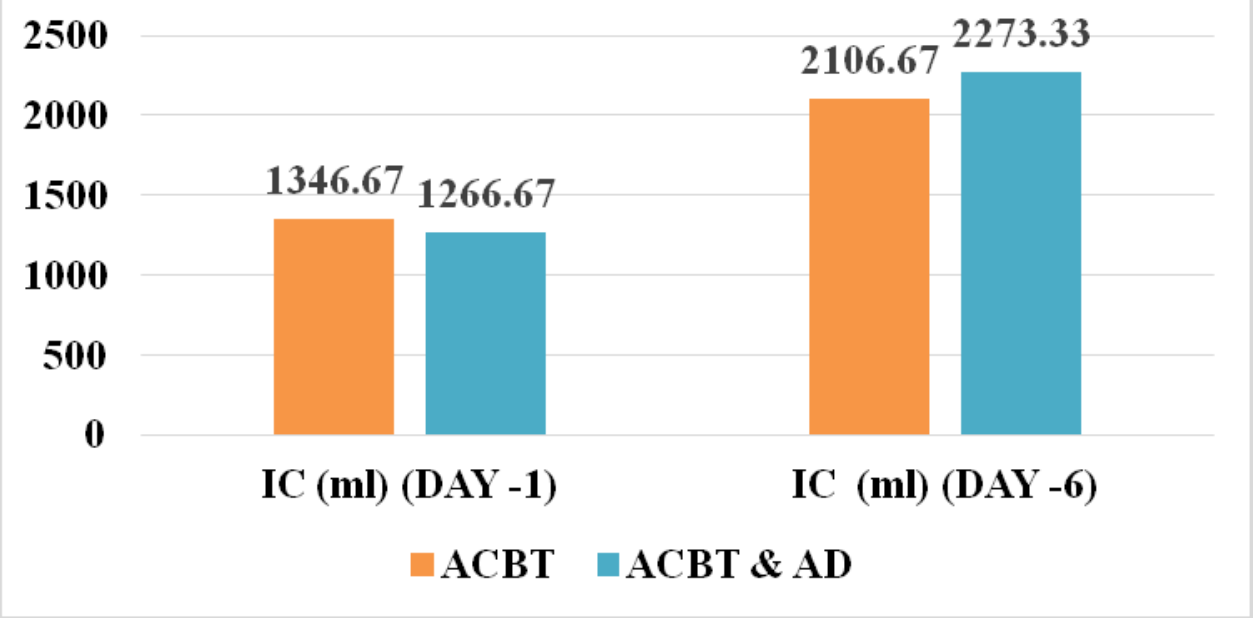


P. S. ManiArasi et.al. Combined effect of active cycle of breathing technique and autogenic drainage on pefr and inspiratory capacity in participants following upper abdominal surgery - a randomized controlled clinical trial study.

\section{DISCUSSION}

Purpose: To evaluate the combined effectiveness of active cycle of breathing technique and autogenic drainage on peak expiratory flow rate and inspiratory capacity in post upper abdominal surgery patients.

The study is shown statistically significant changes in both the groups of upper abdominal surgery participants who had undergone the treatment intervention of Active cycle of breathing technique, incentive spirometry, breathing exercises and Autogenic drainage in the postoperative period over a six days duration. More improvements are noted on the outcome measures of PEFR and inspiratory capacity after six days of intervention.

Post-operative pulmonary complication is common which increases the patient's mortality. Changes in the respiratory system determines the risk factors of complications. These risk factors can be modified or reduced by the immediate post-operative management given to the patient at an early stage which can be aimed in improving the lung volume and clearance of secretions. Early physiotherapy is believed to reduce the pulmonary complications following major surgery. A combined effectiveness of physiotherapy mobilization exercises are beneficial following major surgery ${ }^{[10]}$.Incentive spirometry are prescribed following abdominal surgery that aims to increase the inspiratory volume $^{[11,12]}$.

The beneficial effect following incentive spirometry is found minimal. When there is retention of sputum present post operatively, forced expiratory technique is mandatory to improve the lung volumes and secretion clearance. According to Emily et $\mathrm{al}^{[13]}$, peak flow rate which is the maximum expiratory flow can be used as an indicator of airway calibre. Therefore, measurement of pulmonary function can be checked by measuring the peak expiratory flow.

PEFR values are useful in identifying patients at high risk of developing pulmonary complication $\mathrm{ns}$ in the postoperative period $^{[14]}$.

In our study there is a significant improvement in PEFR and inspiratory capacity in both the groups. In Group A, the mean value of PEFR in day 1 and day 6 are $112.67 \pm 12.23 ; 2106.67 \pm 190.74$ with the " $t$ " value 13.2646 ( $p=0.0001<0.05)$. Thoracic expansion exercises, breathing exercises helps to distend the lungs and increases the collateral ventilation thereby re expanding the lung tissues which may help in mobilising and clearing the bronchial secretions from the peripheral airways $^{[15]}$. This improvement from active cycle of breathing technique in abdominal surgery patients is supported by Wange et $\mathrm{al}^{[16]}$, who concluded that active cycle of breathing technique has a better performance in improving the pulmonary function in abdominal surgery patients by studying 90 patients with two groups of Incentive spirometry and Active cycle of breathing technique for a period of 5 postoperative days. As an outcome measure Peak inspiratory flow rate [PIFR], Peak expiratory flow rate [PEFR], Forced expiratory volume in $1 \mathrm{sec}\left[\mathrm{FEV}_{1}\right]$ and chest expansion were measured which has shown the greater significant improvement in all the parameters and concluded that ACBT is a better technique than Incentive spirometry in post abdominal surgery patients.

The inspiratory capacity in Group A is $1346.67 \pm 168.47$ on day 1 and $2106.67 \pm$ 190.74 on day 6 with the " $t$ " value 11.264 and $\mathrm{p}$ value $0.0001<0.05$. This shows a statistically significant improvement in inspiratory capacity following Active cycle of breathing technique in post-operative period of 6 days following upper abdominal surgery.

Active cycle of breathing technique which consists of repeated cycles of breathing control followed by thoracic expansion exercises and forced expiratory technique. The thoracic expansion exercises with a deep inhalation increases the vital capacity and the breathing control of three second hold in the cycle of inspiration helps 

and inspiratory capacity in participants following upper abdominal surgery - a randomized controlled clinical trial study.

to decrease the collapse of lung tissue This believed to increase the PEFR and inspiratory capacity following active cycle of breathing technique. The present study also can be supported by $\mathrm{J}$ A Pryor ${ }^{[17]}$ who stated that active cycle of breathing technique is the effective in improving the lung function of $\mathrm{FEV}_{1}, \mathrm{FVC}$ and maximum expiratory flow rate at $25 \%$ and $50 \%$ of the FVC.

Autogenic drainage developed by Dab and Chevallier as an airway clearance technique users different expiratory slow at different levels of vital capacity with controlled breathing ${ }^{[18,19]}$.

In our study the peak expiratory flow rate in Group $B$ which includes the intervention of both active cycle of breathing technique and autogenic drainage shown the mean values as $110.67 \pm 13.87$ in day 1 and $338 \pm 52.81$ in day 6 with the " $t$ " value 15.9438 and $p$ value $0.0001<0.05$. This statistical significant difference within the group indicates that the combined effect of active cycle of breathing technique and autogenic drainage has shown a greater improvement in PEFR than Group A which includes only Active cycle of breathing technique. In autogenic drainage there is a gradual increase in inspiratory and expiratory reserve volumes from functional residual capacity. Due to two to three seconds of breath holding through various expiratory flow helps in collateral filling over the alveoli that causes an improvement of ventilation and mobilization of secretions. This helps in lung expansion and prevents airway collapse and decreases the atelectasis $^{[20]}$.

Similarly, the inspiratory capacity In Group B has the mean value in day 1 as $1267.67 \pm 149.6$ and day 6 as $2273.33 \pm$ 201.66 with " $t$ " value 14.1071 and $p$ value $0.0001<0.05$. Inspiratory capacity also has shown the greater improvement following combined intervention of active cycle of breathing technique and autogenic drainage in participants who have undergone upper abdominal surgery. Savci et $\mathrm{a}^{[21]}$ has shown the significant improvement in peak expiratory flow rate following active cycle of breathing technique and autogenic drainage in abdominal surgery patients when the study was made on 30 participants who underwent laparotomy for a period of 7 days. The inspiratory capacity also shown significant improvement over a period of seven post-operative days following active cycle of breathing technique and autogenic drainage. Both the groups shown significant improvement in inspiratory capacity. PEFR has shown greater improvement than Autogenic drainage.

Hence it is proven that the combination of Active cycle of breathing technique and autogenic drainage if prescribed for the surgical patients can benefit in improving lung function than as an individual intervention.

\section{CONCLUSION}

The results of the above study, "Combined effect of Active cycle of breathing technique and Autogenic drainage on PEFR and inspiratory capacity in participants following upper abdominal surgery" shows that there is more improvement of PEFR and Inspiratory capacity on performing both active cycle of breathing technique and autogenic drainage together. Hence, it is mandatory to include active cycle of breathing technique and autogenic drainage in the post-operative period following upper abdominal surgery that improves lung function with reduction in the prevention of pulmonary complications.

\section{Limitation of the study}

- The present study was conducted for a shorter duration, hence short term effects are studied, so lacking long term effects.

- Sample size is less.

- The combined effect of active cycle of breathing technique and autogenic drainage and its relationship in improving PEFR and inspiratory capacity can be studied more in detail in large samples. 
P. S. ManiArasi et.al. Combined effect of active cycle of breathing technique and autogenic drainage on PEFR and inspiratory capacity in participants following upper abdominal surgery - a randomized controlled clinical trial study.

Acknowledgement: None

\section{Conflict of Interest: None}

\section{Source of Funding: None}

Ethical Approval: Approved

\section{REFERENCES}

1. Dr.Miraj Ahmad Dec. 26, 2017 by Abdominal quadrants and its contents. Abdominal organs by region.

2. Rock P, Rich PB. Postoperative pulmonary complications. Curr Opin Anaesthesiol. 2003; 16: 123 -31.

3. Siafakas NM, Mitrouska I, Bourus D, Georgopoulus D. surgery and the respiratory muscles. Thorax. 1999; 54(5): 458-65.

4. Agostini P, Singh S. Autogenic drainage: the technique, physiological basis and evidence. Physiotherapy 2009; 95(2):76-82 .

5. B. Fauroux, M. Boule, F. Lofaso, F. Zer ah, A. Clement, A. HarfChest

Physiotherapy in cystic fibrosis: improved tolerance with nasal pressure support ventilation. Pediatrics, 103 (1999), pp. E321-E329.

6. David A. Autogenic Drainage - the German approach. In: J.Pryor, editor. Respiratory Care, Edinburgh: Churchill Livingstone; 1991.

7. Dougherty and Lister, 2004) Dougherty, L. \& Lister, S. (2004) The Royal Marsden Hospital Manual of Clinical Nursing Procedures, 6th ed. London: Blackwell Publishing.

8. Wanger J, Clausen JL, Coates A, Pedersen OF, Brusasco V, Burgos F, et al. Standardisation of the measurement of lung volumes. Eur Respir J 2005;26(3):511-22

9. Pellegrino R, Viegi G, Brusasco V, Crapo RO, Burgos F, Casaburi R, et al. Interpretative strategies for lung function tests. Eur Respir J 2005;26(5): 948-968.

10. Hanekom S, Brooks D, Denehy L, Fagevik - Olsen M, Hardcastle T,
Manie S, et al. Reaching consensus on the physio therapeutic management of patients following upper abdominal surgery: a pragmatic approach to interpret equivocal evidence. BMC medical informatics and decision making 2012; $6: 12$.

11. Frietas Eliane RFS, Soares Bernado $G O$, Cardoso Jefferson $R$, Atallah Alvaro $N$. Incentive spirometry for preventing pulmonary complications after coronary artery bypass graft. Cochrane database of systematic reviews. 2012.

12. Paulo do Nascimento Junior, Modolo Norma SP, Andrade S, Guimaraes Michele MF.Braz Leandro G, El Did R. Incentive spirometry for prevention of postoperative pulmonary complications in upper abdominal surgery. Cochrane database systemic review.2014.

13. Emily M., et al.: An Evaluation of peak expiratory flow monitoring: A comparison of sitting versus standing measurements. JABFM, 23 (2), 2010.

14. Praveen C. B., Imran Thariq Ajmal. Clinical study of respiratory complications in patients undergoing elective upper abdominal surgery. Int Surg J. 2019 Mar;6(3):732-739

15. Smetana G.W.: Postoperative pulmonary complications: An update on risk assessment and reduction. Cleve. Clin. J. Med., 76 Suppl., 4: S60-5, 2009.

16. Wange $\mathrm{P}$, Jiandani $\mathrm{M}$, Mehta $\mathrm{A}$. Incentive spirometry versus active cycle of breathing technique: Effect on chest expansion and flow rates in post abdominal surgery patients. Int $J$ Res Med Sci. 2016;4(11):4762-6

17. Pryor JA, Webber BA, Hodson ME, Batten JC. Evaluation of the forced expiration technique as an adjunct to postural drainage in treatment of cystic fibrosis. $B M J$ 1979;2(6187):417-8.

18. Dab I, Alexander F. The mechanism of autogenic drainage studied with flow volume curves. Monogr Paediatr. 1979;10: 50-53. pmid:460279 
P. S. ManiArasi et.al. Combined effect of active cycle of breathing technique and autogenic drainage on PEFR and inspiratory capacity in participants following upper abdominal surgery - a randomized controlled clinical trial study.

19. Chevallier J. Autogenic drainage. Cystic fibrosis: horizons. John Wiley \& sons. New York: Lawson D; 1984. p. 235.

20. Melam G.: Comparison of autogenic drainage \& active cycle breathing techniques on $\mathrm{FEV}_{1}$, FVC \& PEFR in chronic obstructive pulmonary disease. World Applied Sciences Journal, 20 (6): 818-822, 2012.

21. Sema Savci, Deniz inal-Ince, Anikan H. A Comparison of Autogenic Drainage and the Active Cycle of Breathing Techniques in Patients with Chronic

Obstructive Pulmonary
$\begin{aligned} & \text { Dournal of cardio } \\ & \text { pulmonary }\end{aligned}$
rehabilitation 20(1): $37-43$.

How to cite this article: P. S. ManiArasi, V. P. Hathila, D. Jayaprakash. Combined effect of active cycle of breathing technique and autogenic drainage on PEFR and inspiratory capacity in participants following upper abdominal surgery - a randomized controlled clinical trial study. Int $J$ Health Sci Res. 2022; 12(2): 26-36. DOI: https:// doi.org/10.52403/ijhsr.20220204 